Session 6-2

\title{
Comparisons of Two Feedback Servo Systems for Control Engineering Education: A Case Study on Student Performance of Speed Control Systems
}

\author{
Zhengmao Ye, Habib P. Mohamadian \\ College of Engineering \\ Southern University \\ Baton Rouge, LA 70813, USA
}

\begin{abstract}
Two sets of experimental equipments with the steady speed motor and tachnogenerator are used to measure the speed response, both of which are products from Feedback Instruments Limited. The 33-110 servo system consists of 3 parts: Mechanical Unit, Analogue Unit and Digital Unit. The 150 servo system has a set of discrete units. The motor is a permanent magnet that is stationary and ideally proportional to the applied voltage when there is no load applied. The tachnogenerator is a small permanent magnet machine which rotates to produce a back EMF proportional to speed, which is used to indicate the rotation speed. The tachnogenerator provides a signal representing speed, independent of the motor loading. The responses of the motor to the varied inputs are not immediately observed which can be recognized as the time constant. Both systems can be used to analyze the stability of system responses. In this article, performance of the two systems are compared and analyzed for control engineering education.
\end{abstract}

\section{Introduction}

Some concepts and technologies in the area of control and optimization should be developed to improve the control system class instruction and laboratory practice, covering most aspects of classical control, modern control and intelligent control theories. In most cases, the cost of a control system increases based on its complexity, thus the optimal performance to cost ratio is desirable ${ }^{1,2,3}$. Proportional controller is the simplest and most intuitive structure for the implementation of linear control systems. So a direct method has been presented ${ }^{4}$ for the determination of the stability range, which is easy to understand, to compute, and to offer the students a better comprehension on this subject. The program in MATLAB language, based on various proposed methods, design examples, and class assessments, has been provided widely in order to help the pedagogical issues. At the same time, online course materials will be helpful for student learning. Since the learning initiative is taken in an e-learning environment, the studentcentered course materials become more critical. The online courses may be prepared based on an individual student's learning expectation and academic background ${ }^{5}$. Building blocks can be developed by open-source software tools and integrated into a single system for the real-life experimental study. Based on a specific application of the quality philosophy in the development

\footnotetext{
Proceedings of the 2008 ASEE Gulf-Southwest Annual Conference

The University of New Mexico - Albuquerque

Copyright (C) 2008, American Society for Engineering Education
} 
of digital electronics laboratory courses, two main goals can be achieved to provide students with a methodology to manage problems and start a process of continuous improvement ${ }^{6,7,8}$. The interdisciplinary nature of control laboratory course allows for its applications in subjects of broad disciplines like electrical, mechanical, automotive and biomedical systems.

\section{Experimental Systems}

A permanent magnet type of motor has been selected. When the motor is stationary and a voltage $\mathrm{V}_{\mathrm{S}}$ is applied, a current flow $\mathrm{I}_{\mathrm{A}}$ is generated which causes the motor to rotate. As the motor rotates, a back EMF $\mathrm{V}_{\mathrm{B}}$ occurs. As the motor speeds up, the back EMF increases and $\mathrm{I}_{\mathrm{A}}$ drops. For an ideal motor, the armature current falls to substantially zero and $V_{B}$ approximately equal $\mathrm{V}_{\mathrm{A}}$. Thus, if $\mathrm{V}_{\mathrm{A}}$ is varied slowly in either polarity, the motor speed is proportional to $\mathrm{V}_{\mathrm{A}}$. In both 33-100 and 150 servo systems (Figures 1-2), the armature voltage $\mathrm{V}_{\mathrm{A}}$ is provided by a power amplifier. It is necessary because although the voltages in the error channel may be of the same order as $\mathrm{V}_{\mathrm{A}}$, the motor current may be up to $1 \mathrm{~A}$, while the error channel operates with currents of less than $1 \mathrm{~mA}$ and could not drive the motor directly. The amplifier has two input sockets, enabling the motor rotation direction to be reversed for a specific input. The tachogenerator is a small, permanent magnet machine and hence when rotated produces an EMF proportional to speed which can be used as a measure of the rotation speed. The permanent magnet DC motor can be controlled by varying the magnitude and direction of its armature current. The motor has a single armature winding, current flow through the armature is controlled by power amplifiers.

The 33-100 servo system consists of Analogue Unit, Mechanical Unit, DC Power Supply ( $\pm 15 \mathrm{~V}$ and $+5 \mathrm{~V}$ ) and Oscilloscope. The 150 servo system consists of Attenuator Unit, Servo Amplifier, Power Supply, DC Motor, Loading Unit, Reduction Gear Tacho Unit and Baseplate. The 33-100 servo system provides magnetic eddy current brake for changing the level position representing adjustable torques for different loading levels. The 150 servo system also has the magnetic brake with a permanent magnet which can be swung over an aluminum disc. When the disc is rotated eddy currents circulate in the area of the disc within the magnet gap and these react with the magnet field to produce a torque which opposes rotation. This gives adjustable torque speed relation and provides a very convenient load for the motor. The brake is provided in order to show that the steady speed of the motor is ideally proportional to the applied voltage, less an amount proportional to load torque. In addition, it helps to learn that DC tachogenerator provides a signal representing speed, independent of motor loading, also the response of the motor to a change of input is not immediate, but is expressed as a time constant (time delay). The overall characteristics of a motor may be considered from two aspects: Steady-state, which are concerned with constant or very slowly changing operating conditions; Transient, corresponding with sudden changes. Both steady state and transient responses are important in control system applications. The main objectives are: to appreciate how a permanent magnet DC motor may be controlled by varying the magnitude and direction of its armature, to recognize torque and speed characteristic and to establish the tachogenerator scaling factor.

\footnotetext{
Proceedings of the 2008 ASEE Gulf-Southwest Annual Conference

The University of New Mexico - Albuquerque

Copyright (C) 2008, American Society for Engineering Education
} 


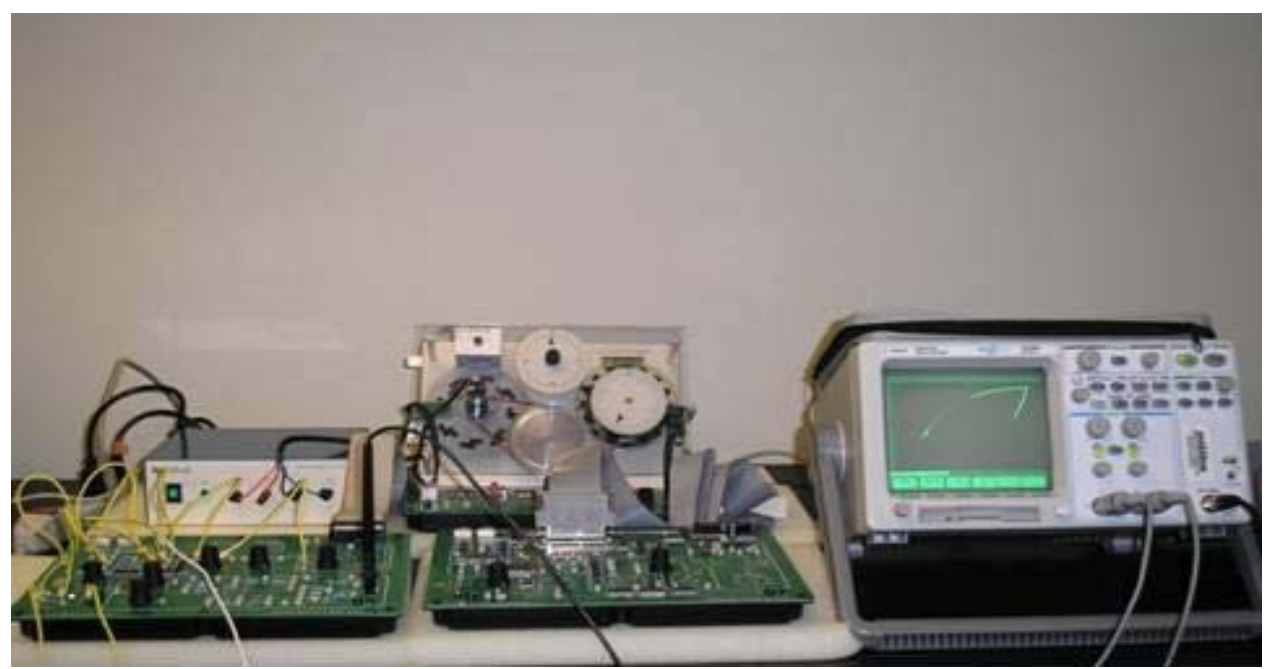

Figure 1. 33-100 Servo System Demonstration - (X-Y) Display

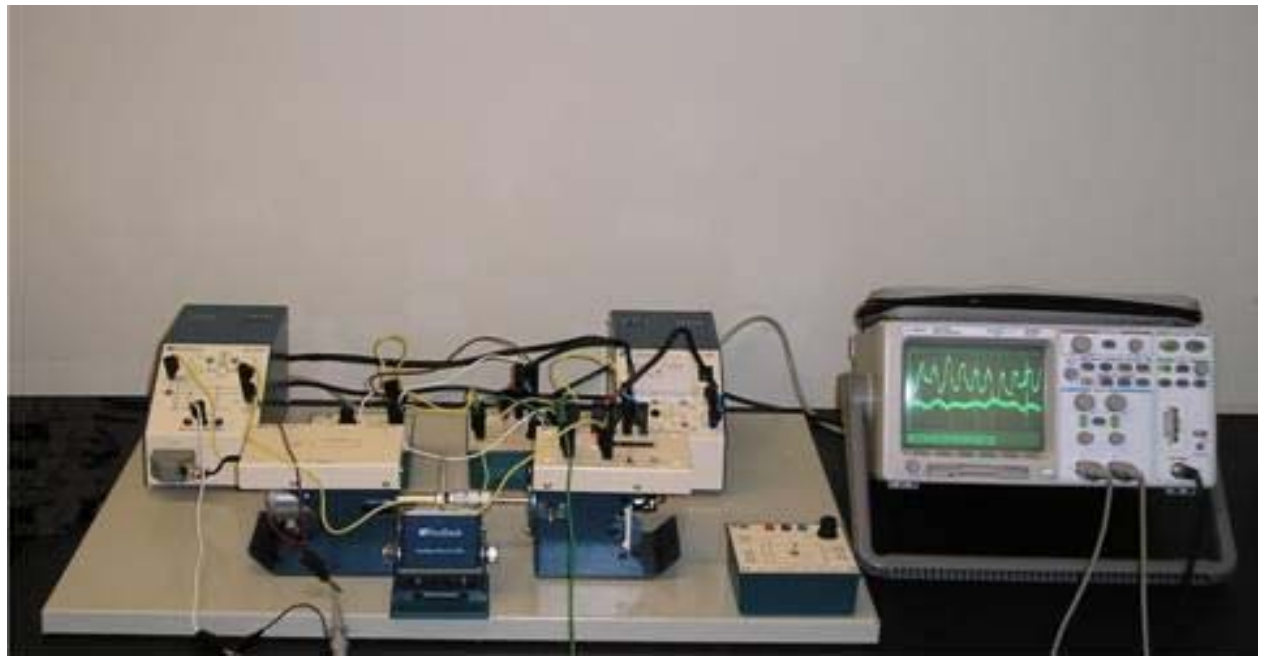

Figure 2. 150 Servo System Demonstration - V(t) Graph Display

\section{Experimental Procedures}

\section{33-100 Servo System}

The analogue and mechanical units in the 33-100 servo systems should be connected together by the 34-way ribbon cable. The power supply should be connected by $4 \mathrm{~mm}$ plug, which leads to the $+15 \mathrm{~V},+5 \mathrm{~V}, 0 \mathrm{~V}$ and $-15 \mathrm{~V}$ sockets at the back of the mechanical unit. 


\section{A. Steady State Characteristics Measurement}

Arrange the system gain so as to enable a voltage in the range $\pm 10 \mathrm{~V}$ to be applied to the power amplifier. Use the DVM (Range: +/-20V) for voltage measurements. Set up the required steady state for each measurement. Then switch between DVM and RPM for voltage and speed. By varying the gain, make a plot of motor speed against the amplifier input, in the range $\pm 10 \mathrm{~V}$, scaling the vertical axis in units of 1000r/min. Plot the tachogenerator characteristics by setting the motor speed to various values by the gain and measuring the generated voltage. Determine the tachogenerator factor by measuring a change in generated volts for a speed change of $1000 \mathrm{r} / \mathrm{min}$. When brake load is added, steady state characteristics will change accordingly. Adjust the gain again by setting the motor speed to 2000r/min. Connect the DVM to the armature current output on the Mechanical Unit. Set the brake level to each of its six positions in turn. Then for each setting, record and plot the speed and armature current.

\section{B. Transient Response Characteristics Measurement}

Connect the system which enables the motor to be driven from the square-wave, and allows the speed to be displayed on the $\mathrm{Y}$ axis of an oscilloscope. Set the gain to zero and set the test signal frequency to be $0.2 \mathrm{~Hz}$. Set the power amplifier adjustment to run the motor at maximum speed in one direction. Turn up the gain and the square-wave signal to speed up and slow down the motor. Adjust this gain until the motor is stationary for one half cycle. The oscilloscope will now display the speed corresponding with armature voltage. If the applied voltage is suddenly changed, the motor does not respond instantly. Its time constant is defined as the time it would take to reach its final speed if the initial acceleration is maintained. It can be estimated by considering the initial slope and maximum speed. The motor time constant value should be in the region of $0.5 \mathrm{~s}$.

\section{150 Servo System}

Attach the 150 servo system to the Baseplate by means of the magnetic fixings. Place the aluminum eddy-current disc at the midway in the gap of magnetic brake with its edge flush with the back of the magnet. Use the switch on the top of the GT150X to display the volt or speed as required. Set the magnetic brake to the unloaded position and turn the potentiometer until there is a reading of $1 \mathrm{~V}$ on the voltmeter. Repeat the readings with a $2 \mathrm{~V}, 3 \mathrm{~V}, 4 \mathrm{~V}$, and $5 \mathrm{~V}$ generator output. Record the speed and plot a graph of speed against tachogenerator volts. The calibration factor is $\mathrm{Kg}=\mathrm{Vg} / \mathrm{N} \mathrm{r} / \mathrm{min}$. It is about 2.0-3.0V per $1000 \mathrm{r} / \mathrm{min}$. Find the slope of the speed/input volts curve without a load. Reduce the input voltage until the motor is just turning, then measure the voltages of the tachogenerator output. Increase the input voltage in one-volt steps, take readings of the input voltage and tachogenerator voltage up to approximately $2000 \mathrm{r} / \mathrm{min}$, which is the maximum speed of the motor. Calculate the slope. Fix the brake so that it passes over the eddy-current disc smoothly while the motor is running to measure the torque/speed characteristics. Set the brake at position 0 and increase the input voltage until the motor rotates at close to its maximum speed. Set the brake position and if necessary reduce the input voltage so that the ammeter is just below 2 amps. Take tachogenerator readings over the range of the brake down to zero position. Reset the brake back to maximum position and reduce the input voltage so that the motor is slowly rotating. Plot results of speed against torque (brake location) for different input voltage values.

\footnotetext{
Proceedings of the 2008 ASEE Gulf-Southwest Annual Conference

The University of New Mexico - Albuquerque

Copyright (C) 2008, American Society for Engineering Education
} 


\section{Experimental Results and Analysis}

For both 33-110 servo and 150 servo systems, the motor speed is roughly proportional to the applied voltage when external load (brake) is not added. Using the brake, we have $\mathrm{Va}=\mathrm{Vr}+\mathrm{Vb}$ $=\mathrm{IaRa}+\mathrm{Vb}$, where $\mathrm{Va}$ is the input voltage, $\mathrm{Vb}$ is the back EMF, Ra represents the armature resistance and Ia represents the current at different levels of brake. In Figures 3-4, some results from the 33-110 and 150 servo systems are given. The X-Y display of transient response in the 33-110 servo system can be seen in Figure 1. Comparing the 33-110 servo and 150 servo systems, the 33-110 servo system has a compact experimental unit system with the novel integrated circuit design. It will take shorter class time for students to conduct experiments completely. On the other hand, measurement of Steady State Response and Transient Response Characteristics can both be conducted at the same time. The advantage of the 150 servo system is that physical mechanisms can be directly shown from the layout of experimental connections, where the discrete circuit unit components are employed. This system also has a vivid loading system (magnetic eddy-current disc for back EMF). It takes a little longer class time to help student in quick learning, while the transient response part has not been design in this system.
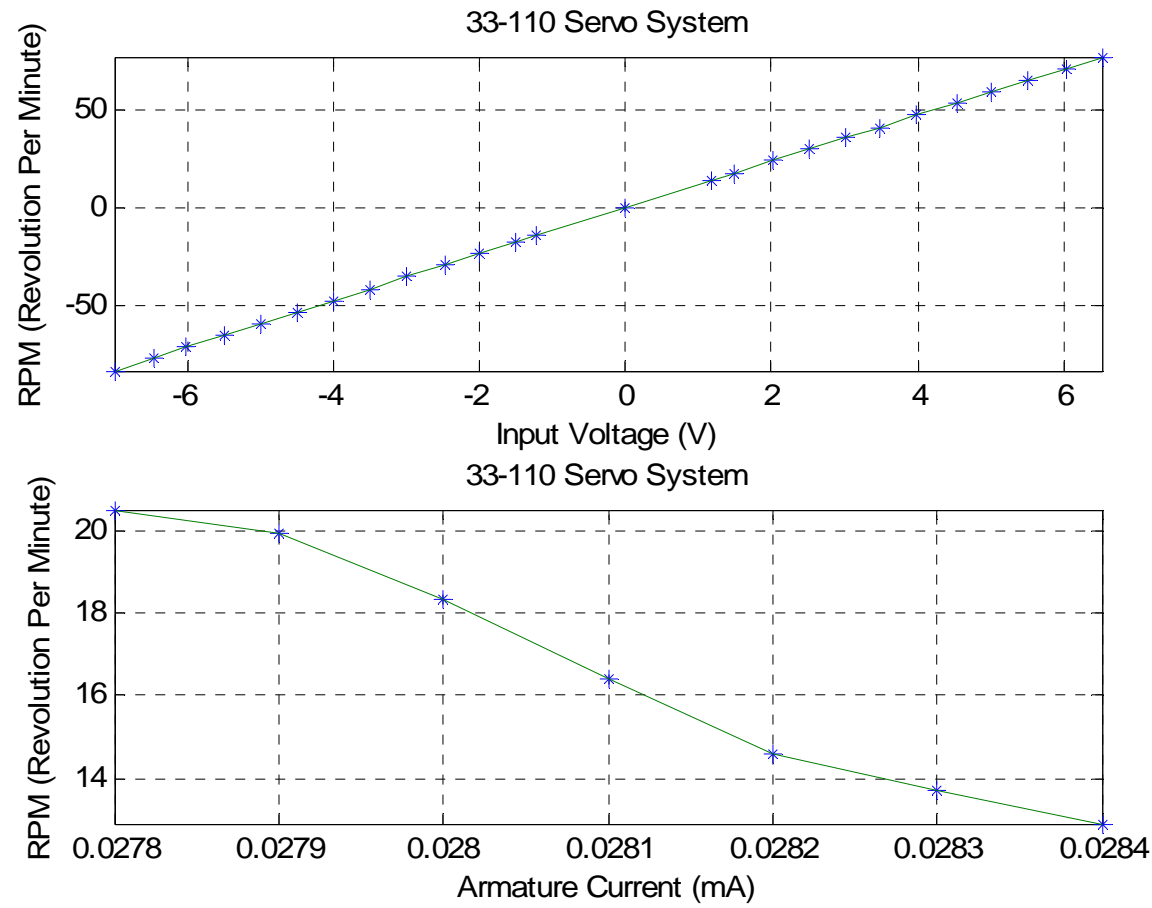

Figure 3. An Example of 33-110 Servo System Testing Results

Proceedings of the 2008 ASEE Gulf-Southwest Annual Conference

The University of New Mexico - Albuquerque

Copyright (C) 2008, American Society for Engineering Education 

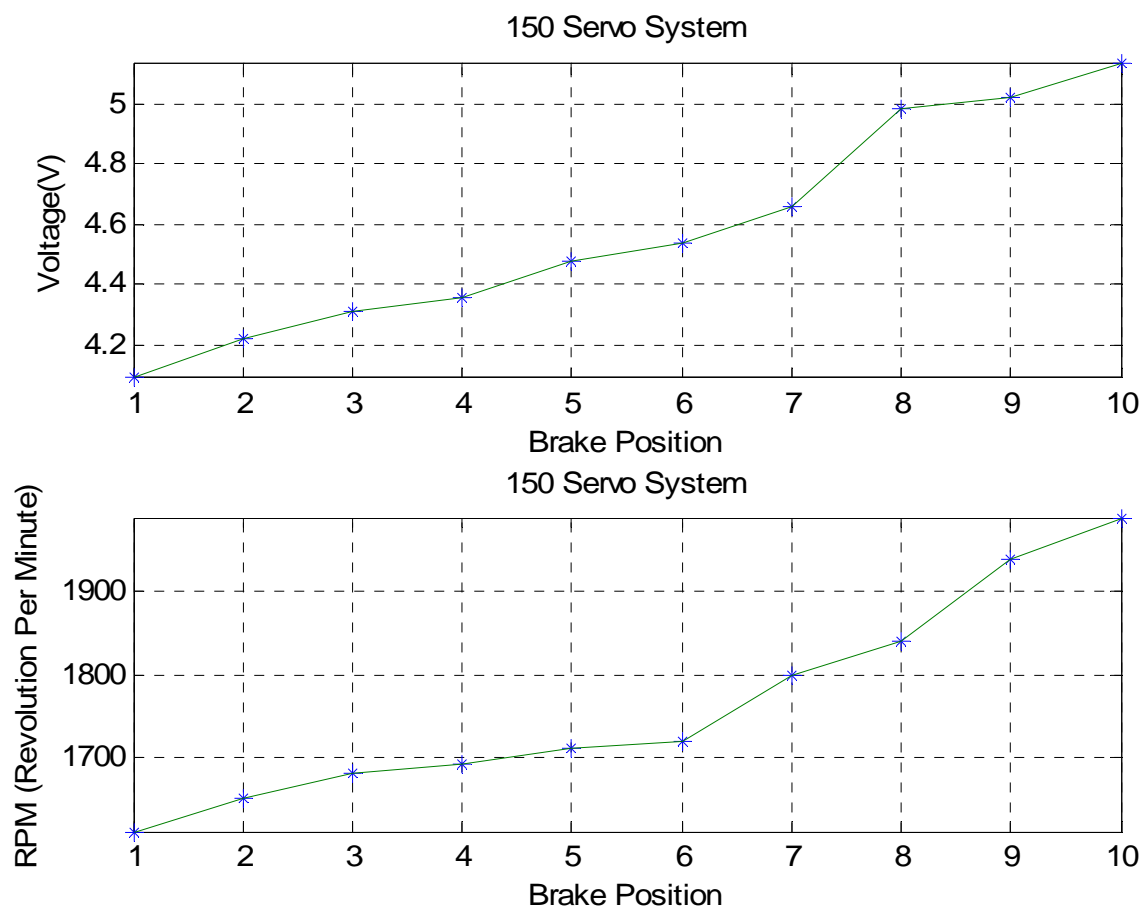

Figure 4. An Example of 150 Servo System Testing Results

\section{Conclusions}

For both servo systems, the motor has a speed roughly proportional to the applied voltage with no load. The armature current increases with increasing load torque, causing a voltage drop in the armature resistance. This effectively reduces the applied voltage, causing a drop in speed. The magnetic brake provides a torque proportional to speed and dependent on the overlap between the magnet and the disc. The slowing up process associated with reverse current assumes that the reverse current can be returned through the voltage source. Otherwise the motor takes a much longer time to slow down. If the armature resistance is low, the initial armature current may be very large. Thus the equipment is used to limit the current while the motor is being run up to speed. This applies especially with large motors. With armature control, the negative feedback of the back EMF will oppose the input signal and tend to maintain a steady motor current. This will result in a more constant speed over the torque range. Both servo systems have its advantages and it is suggested that students take experiments on both systems in order to fully grasp theoretical control engineering knowledge instructed in lecture courses. 


\section{References}

1. Z. Ye, H. Majlesein, P. Bhattacharya and H. Mohamadian, "Exploring Multi-Objective Optimization to Enhance Sensor Integration Technology for Course Instruction and Laboratory Development", Proceedings of the 2006 ASEE Gulf Southwest Annual Conference, March 15-17, 2006, Baton Rouge, USA

2. Jurado, Francisco; Castro, Manuel; "Experiences with fuzzy logic and neural networks in a control course”, IEEE Transactions on Education, v 45, n 2, May, 2002, p 161-167

3. Yurkovich, S., Passino, K.M., "A laboratory course on fuzzy control”, IEEE Transactions on Education, v 42, n 1, Feb. 1999, p 15-21

4. M. Teixeira, E. Assunção, and M. Covacic, "Proportional Controllers: Direct Method for Stability Analysis and MATLAB Implementation", IEEE TRANSACTIONS ON EDUCATION, VOL. 50, NO. 1, FEBRUARY 2007

5. E. Leung and Q. Li, "An Experimental Study of a Personalized Learning Environment Through Open-Source Software Tools", IEEE TRANSACTIONS ON EDUCATION, VOL. 50, NO. 4, NOVEMBER 2007

6. I. Plaza, and C. Medrano, "Continuous Improvement in Electronic Engineering Education", IEEE TRANSACTIONS ON EDUCATION, VOL. 50, NO. 3, AUGUST 2007

7. Hagler, M.O., Marcy, W.M., etc, "The making of the special issue on the application of information technologies to engineering and science education", IEEE Transactions on Education, Volume 39, Issue 3, Aug. 1996, Page(s):450 - 451

8. Z. Ye, Control System Lab Manuals (Vol. 1, Vol. 2), Southern University, November, 2005

\section{ZHENGMAO YE}

Dr. Ye currently serves as an Assistant Professor of Electrical Engineering at Southern University. Dr. Ye's research interests include modeling, control and optimization with diverse applications on automotive, electrical, mechanical and biomedical systems, as well as signal processing and image processing. Dr. Ye is a Senior Member of IEEE and the Founder and Director of System and Control Laboratory at Southern University. Historically, Dr. Ye is among first ever cross-disciplinary researchers with the first author publications covering all leading control proceedings in three prestigious engineering societies (IEEE, ASME, SAE), specifically, IEEE (SMC, CDC, CCA, ACC, ISIC, FUZZ, IJCNN, CASE, ICCA, SOSE and CCECE), ASME (Congress IMECE, ICES, JRCICE), SAE (Congress USA, EAEC, PFL), and with sole authorships in IEEE Transactions and SAE Transactions as well.

HABIB P. MOHAMADIAN

Dr. Mohamadian currently serves as the Professor and Dean of College of Engineering at Southern University and A \& M College. The Dean oversees the College's strategic planning, program development, academic affairs, government/industry relations, and research initiatives. Dr. Mohamadian's research interests include diverse areas of Mechanical Engineering.

Proceedings of the 2008 ASEE Gulf-Southwest Annual Conference

The University of New Mexico - Albuquerque

Copyright (C) 2008, American Society for Engineering Education 